\title{
Evaluation of surface mining areas through geospatial analysis. The case of Ptolemais lignite mines
}

\author{
Aikaterini Servou ${ }^{1,2}$, Nikolaos Paraskevis ${ }^{1}$, Christos Roumpos ${ }^{1}{ }^{*}$, and Francis Pavloudakis ${ }^{1}$ \\ ${ }^{1}$ Public Power Corporation of Greece, Department of Mining Engineering, 10432 Athens, Greece \\ ${ }^{2}$ University of Patras, Department of Geology, 26504 Patras, Greece
}

\begin{abstract}
The lignite surface mines often occupy large areas to develop the mining activities: pits, dumping areas, bunkers, buildings, workshops, and other auxiliary facilities. The land reclamation methods and the corresponding land use alternatives after the mine closure constitute an important part of an integrated mining planning. In the present contribution, the main parameters of geospatial planning are investigated in order to assess the changes in land uses in a mining area and to correlate them with the spatiotemporal development of the extraction works. As a case study, geospatial analysis of the current situation in Ptolemais mines is presented. In particular, seven dumping areas are assessed regarding their suitability for specific land uses. The assessment is based on the following criteria: a) slope gradient, b) reclamation works already completed, c) slope aspect, d) proximity to the road network, and e) proximity to residential areas. Furthermore, the ArcGis software is used to compile the layer maps of the corresponding parameters.
\end{abstract}

\section{Introduction}

The land cover and use changes are significant factors that directly affect various economic activities and modify the earth's global and regional climate and environmental conditions. Many land cover/use research results have been identified through international literature review, concerning the urban and marine environment, but few about surface mining areas. However, the analysis and monitoring of these changes could contribute to developing the sustainability of mining and land planning decision-making [1-6]. Besides, land cover and use studies provide valuable information that can be used for updating land management strategies [7].

Land cover is the physical material at the earth's surface, whereas land use involves managing and modifying the natural environment by human activity. Land use by humans has a long history, first emerging more than 10 thousand years ago. These two terms are often erroneously used interchangeably; however, each term has a particular meaning [8]. Land cover can be determined by analyzing satellite and aerial imagery, whereas land use cannot.

\footnotetext{
*Corresponding author: c.roumpos@dei.com.gr
} 
As far as the operation of large-scale surface mining activities is a concern, a typical sequence of long-term surface mining stages concerning the mining life cycle and land cover and use changes is illustrated in Figure 1. According to Kumar et al. 2013, surface mining-induced land use changes occurred predominantly at the expense of cropland and forest land [9]. Most of the land cover changes occur in the cropland with a declining trend as mine production increases, while an increase in the forest land occurs due to the forestation of reclaimed dumps carried out in the frame of mine's environmental permits.

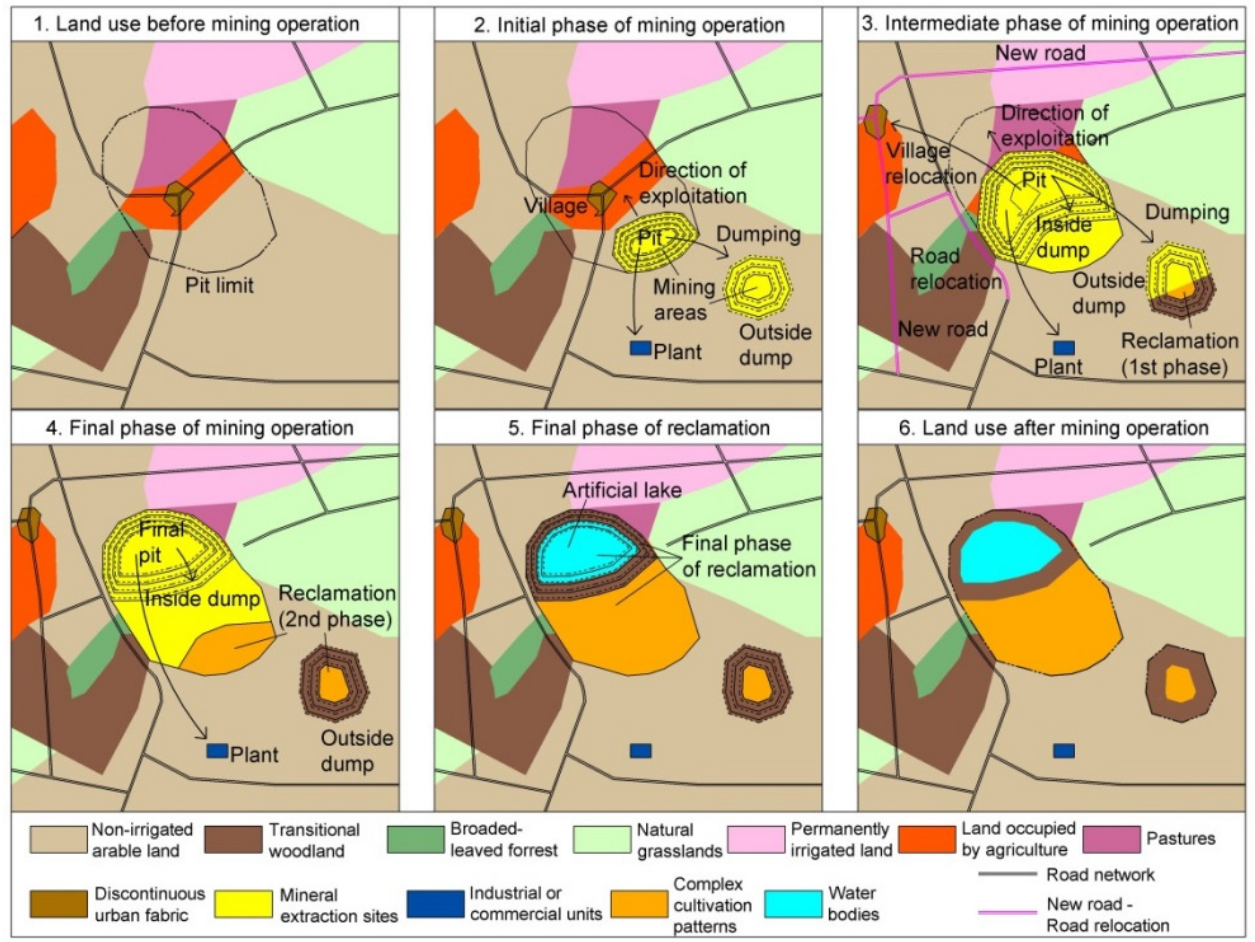

Fig. 1. Surface mine development and land cover/use changes.

In the international literature, for the determination of post-mining land uses several methods are used, which are based on criteria ranking techniques and opinion experts. Masoumi et al. 2014 [10], use a combination of a fuzzy and AHP technique for ranking and weighting the criteria respectively. The fuzzy techniques face the uncertainties which are included in the decision-making. Another combination for addressing the uncertainties is that of Grey relational analysis (GRA) with Analytical Hierarchy Process (AHP) [11,12]. The GRA method gives the solution in handling the uncertainties and risk which are included in the evaluation of the most suitable land use. Furthermore, multi-attribute decision-making techniques are applied [13]. Ordered weighting averaging (OWA) is a multi-criteria evaluation method that uses fuzzy (linguistic) quantifiers in a GIS environment. By making different operators' combinations, a wide range of decisionmaking is achieved [14].

The main research question that tried to be investigated in this study focused on the selection of the appropriate land properties that determine the suitability for several land uses (agricultural, forest, photovoltaic, industrial - recreation land uses). 


\subsection{Study area}

The suitability evaluation of post-mining soils for land uses is a fundamental and integrated procedure for a sustainable mining project. In the present study, the case of Ptolemais mines is investigated. The Ptolemais mining area is characterized as a complex system that is consisted of mines, dumps, reclaimed land, villages, infrastructures, roads, railway lines, and rivers. The exploitation of lignite mines by the Public Power Corporation (PPC) of Greece, in the Ptolemais mining area (Kozani Province of Western Macedonia Prefecture, northern Greece) started in 1957. The study area is defined within Approved Environmental Permitting Limits of Ptolemais mines $\left(147.91 \mathrm{~km}^{2}\right)$. It includes the excavation areas of surface mines in operation, the inside and outside dumping areas, former mining areas (exhausted mines and dumping areas) that have been reclaimed, as well as buildings and auxiliary facilities. There were selected seven dumping sites of the mining area that are already completed since December 2020 (Figure 2). Today, reclamation works have already been carried out in the mining area, while some areas are still in operation.

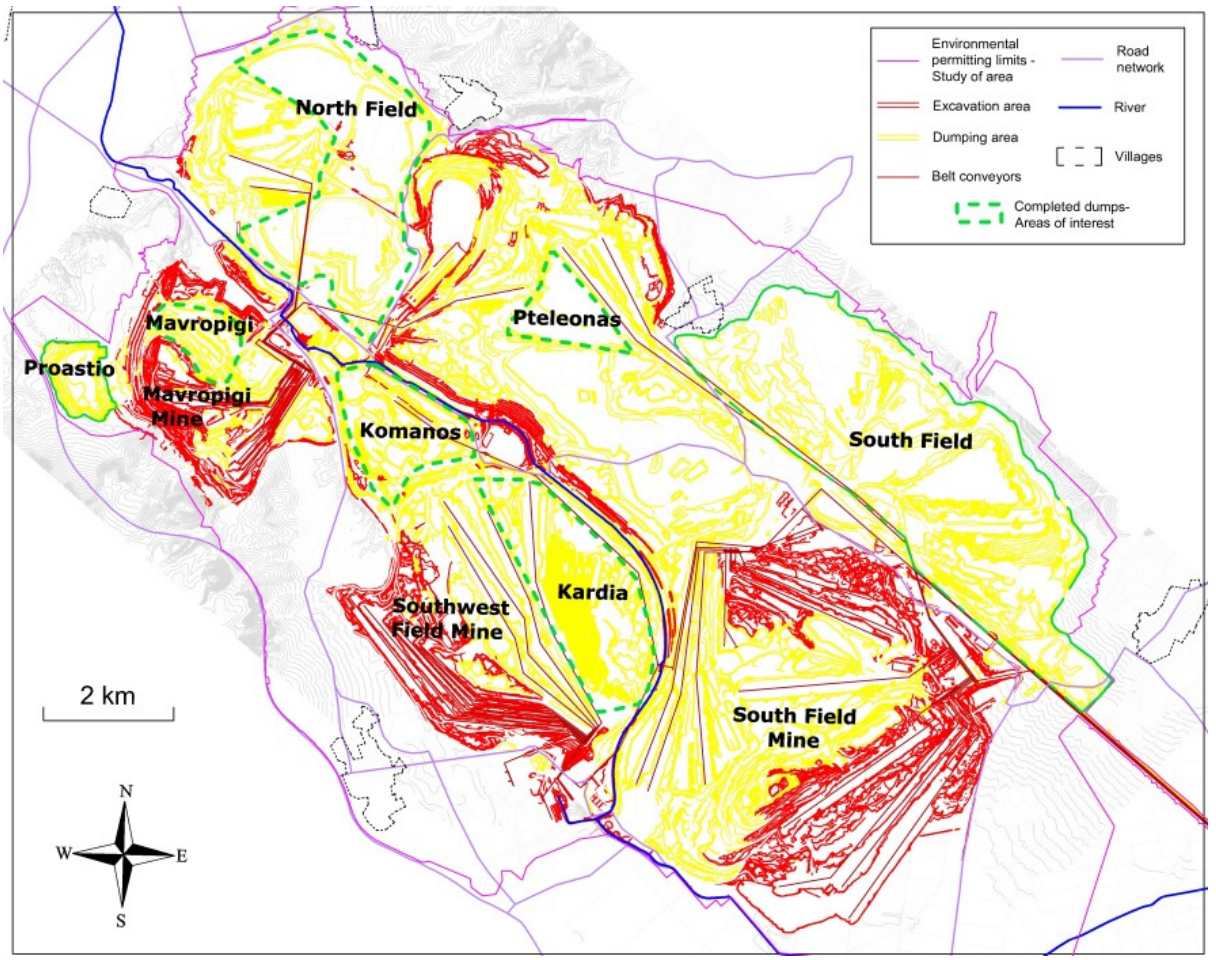

Fig. 2. The study area with the dumping sites of interest.

\section{Materials and Methods}

A crucial step in the land suitability analysis is to select the appropriate evaluation criteria. The selection of the criteria depends on the study area characteristics. Some of the criteria categories could be topographical, environmental, socioeconomic, etc. In the study of Pavloudakis et al. 2009 [15], the criteria are distinguished into those that present spatial character and those which do not. However, the criteria have different importance to each other regarding the study land uses. For this reason, several methods are offered for addressing the relative importance [16]. Such methods are "ranking", "rating", "pairwise 
comparison" and "trade-off". The combination of the factor maps with the factor value (attribute) and decision maker's preferences is the main procedure for the land suitability assessment [14].

The criteria that have been selected for the present study are the following: altitude, slope surface, slope aspect, proximity to the road network, proximity to villages, and current land cover/use as it has been interpreted from Corine satellite images. Moreover, the land uses that have been selected for investigation are agricultural, forest, photovoltaic, and industrial-recreation parks. The latter land use implies the areas deemed suitable to accommodate residential and/or industrial and/or recreation areas and/or other activities that enhance the economic activities and living standards of the inhabitants of the greater mining area.

For each one of the criteria have been determined ranges of values that favour, hinder or even exclude certain land uses. For example, the slope surface angle is to be minimized for agricultural use; meaning the lower the value of slope surface, the higher suitable the land is. Conversely, for forest land use, higher values of slope surface are not excluded from the suitability assessment. In addition, proximity to rivers is a criterion to be minimized, as the closer to the villages a land area is the better for agricultural use.

The study area was classified into cells with a size of 94 x $94 \mathrm{~m}$, as the cell size of DEM obtained by Public Power Corporation (PPC) data. The criterion maps were derived by calculating the Euclidean distance using the Spatial Analyst tool of ArcGIS software, regarding the proximity analysis parameters (Equation 1).

$$
d(p, q)=\sqrt{\left(q_{1}-p_{1}\right)^{2}+\left(q_{2}-p_{2}\right)^{2}}
$$

Where $p_{1}, p_{2}$, and $q_{1}, q_{2}$ the Cartesian coordinates of point $\mathrm{p}$ and $\mathrm{q}$ respectively.

Parameters such as slope surface, slope aspect, and altitude were derived by the DEM processing of the study area. The available study data are both raster and vector types. Rasterization was applied for the vector data because raster models are considered more appropriate for land-use suitability applications. Specifically, for the proximity analysis, buffer and Boolean operations, and overlays, the raster models are more easily implemented [17]. Furthermore, the statistical analysis that was implemented for the criteria was based on the raster cells of all dumps.

\section{Results and Discussion}

The diagrams of Figures 3-7 were extracted from the raster cells analysis for each factor that was conducted in the GIS software. The statistical distribution of elevation factor (Figure 3) shows that the higher concentrations of the values are between 650 and 720 meters, as well as 770- 870 meters. Higher altitudes are exposed to lower temperatures and higher wind speeds that prohibit certain agricultural activities. In Figure 4 the majority of the cell count sample seems to occupy the first slope classes, meaning $0-8^{\circ}$. These slope values are considered highly suitable $\left(0-2^{\circ}\right)$ to moderate suitable $\left(2-8^{\circ}\right)$ for agricultural use [18]. The slope aspect presents a high concentration between the values $170^{\circ}$ and $270^{\circ}$, which include a range of slope aspects that are considered favourable for Greece (Figure 5). However, the optimal slope aspect for photovoltaic use depends on the local conditions of the area, such as the solar radiation. The "proximity to roads and villages" are two factors that affect especially the decision for photovoltaic and industrial - recreation land uses. The majority of the values for the "proximity to roads" factor are concentrated until $500 \mathrm{~m}$ (Figure 6). The roads' proximity regarding the agricultural land use is considered as a positive condition because the closer to the road, the easier access to their rural areas people 
will have. Furthermore, this factor is to be minimized too, for the industrial - recreation land uses. The "proximity to villages" does not present a homogeneous distribution, but from a general point of view, the majority of the values present to be close to the $2.5 \mathrm{~km}$ (Figure 7). This distance is considered suitable for industrial land uses. On the contrary, areas that are close to villages and are exposed to view from neighboring villages due to their slope aspects must be excluded from the development of photovoltaic parks in order to avoid the degradation of the aesthetic value of the landscape.

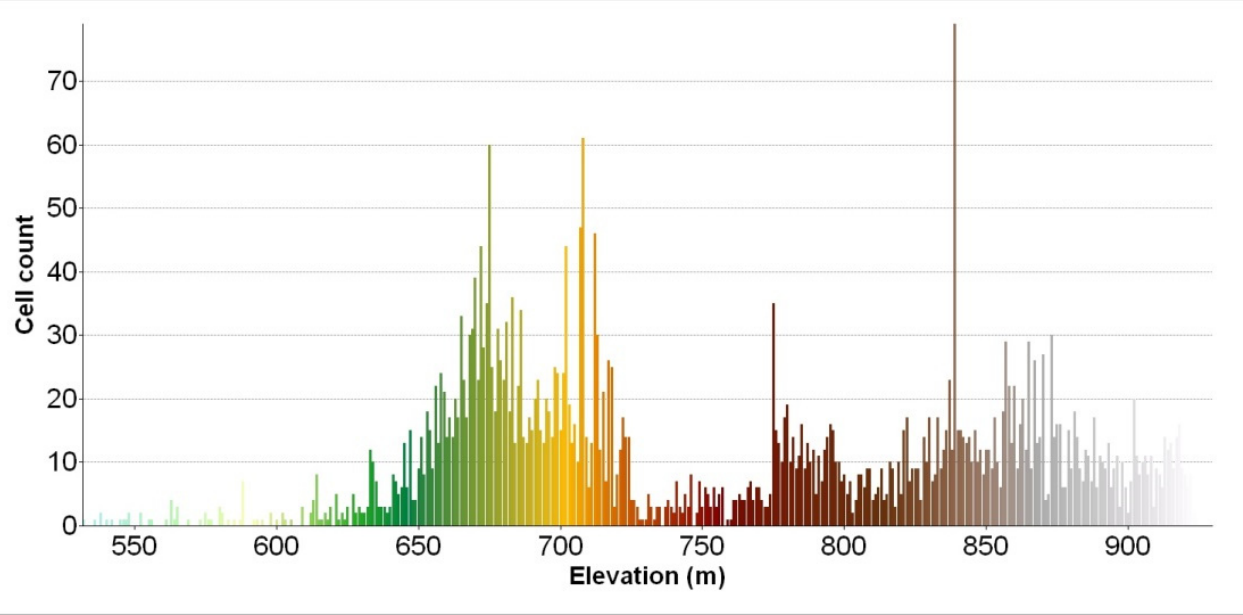

Fig. 3. Statistical distribution of "elevation" factor.

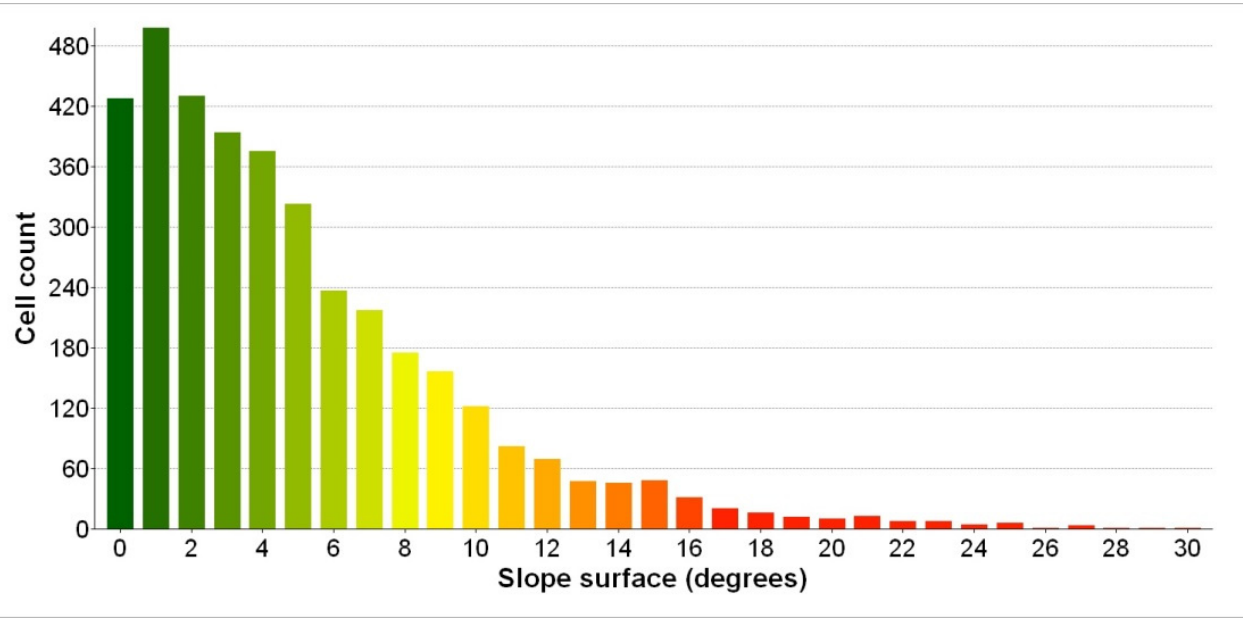

Fig. 4. Statistical distribution of "slope surface" factor. 


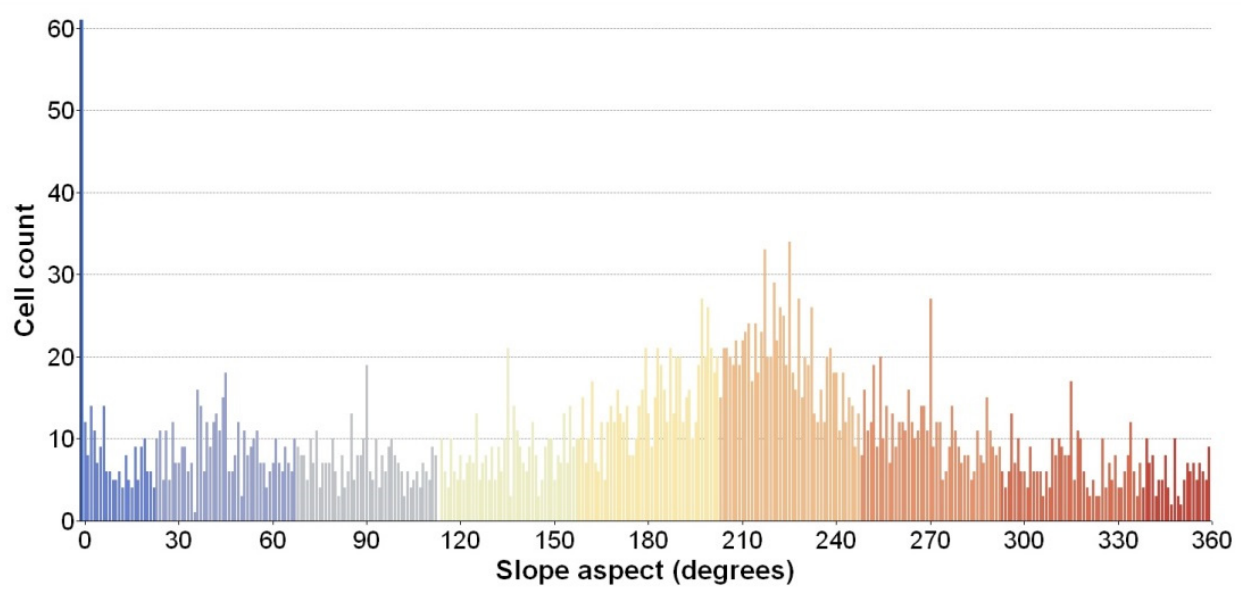

Fig. 5. Statistical distribution of "slope aspect" factor.

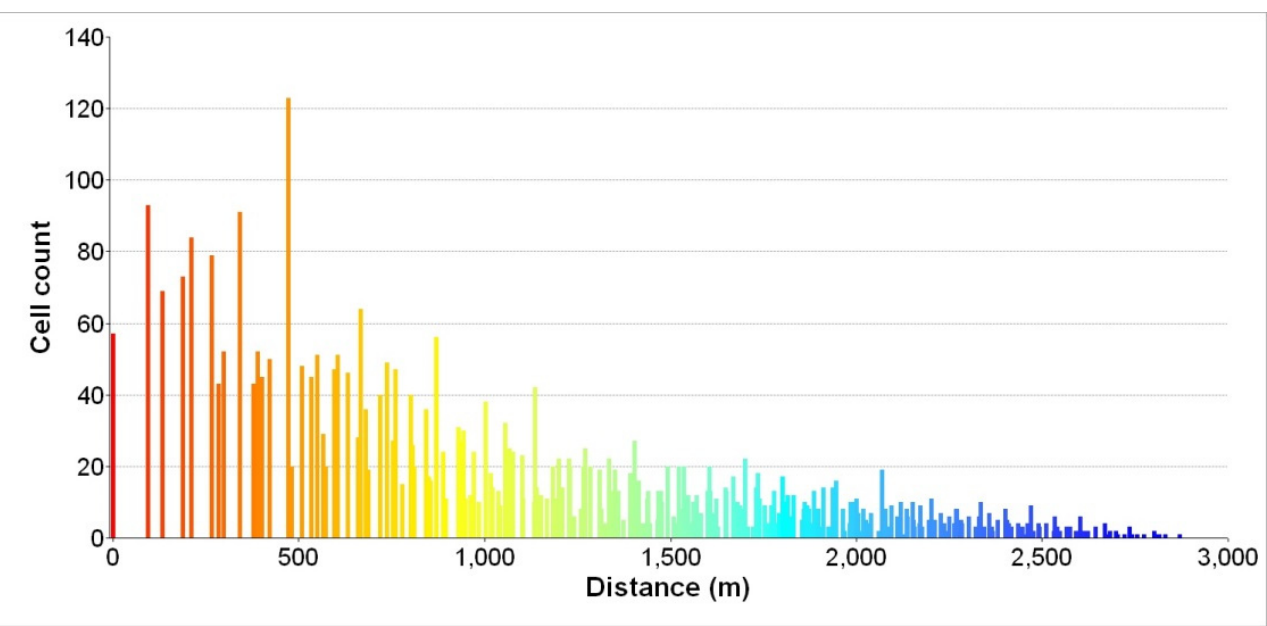

Fig. 6. Statistical distribution of "proximity to roads" factor.

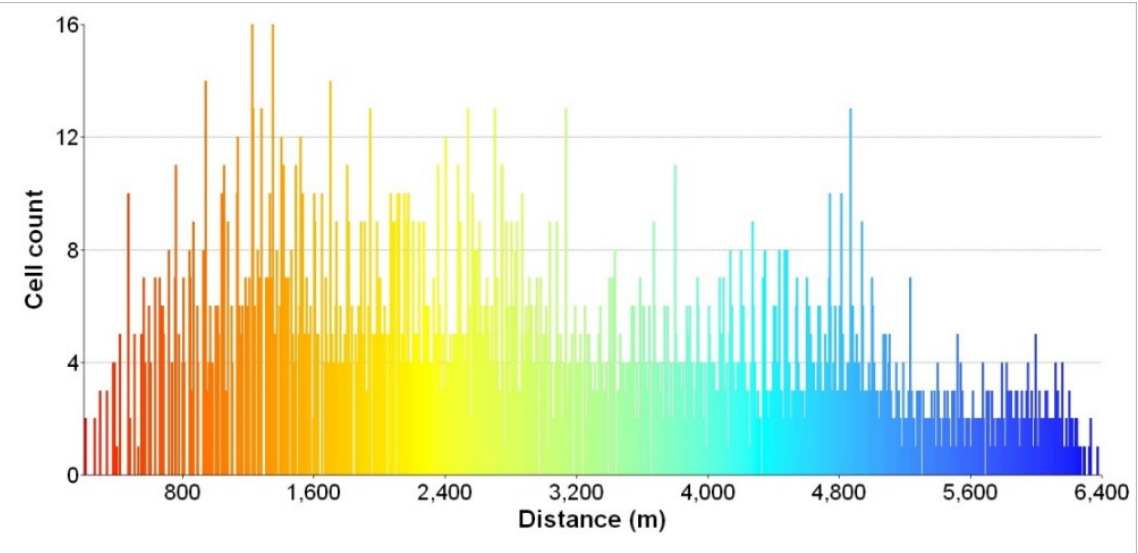

Fig. 7. Statistical distribution of "proximity to villages" factor. 
The six selected evaluation criteria were spatially distributed in the dumping sites and depicted in Figure 8. Forests could be created in gentle slope surfaces but in higher too. Since there are no strict restrictions on the slope criterion for forest land use, agricultural use is firstly investigated. It is observed that the higher elevation values are concentrated in the Pteleonas and South Field dump. In the South Field dump, the higher slope values are also concentrated. This criteria combination shows directly that some parts of these dumps do not favour agricultural use. However, only a small area of the South Field dump is characterised as unsuitable for agricultural land use. The remaining area of this dump as well as the dump of Pteleonas are not excluded from agricultural land use, but they are considered as more appropriate for other land use, such as forest or photovoltaics. Furthermore, Proastio and Mavropigi dumps are characterized in the most part from steep slopes and consequently are proposed for forestation.

Regarding the photovoltaic land use, the most important criteria are the slope surface, and the slope aspect, meaning that in steep slopes the photovoltaics installation is not preferred, while the optimal slope aspect depends on the local conditions of the area.

The Corine land cover/use 2018 dataset includes the already reclaimed land until 2018 and the land that has not been yet reclaimed, which is characterised as artificial. In the general case, the importance of each factor is quite relational and subjective.

The Kardia dump has a higher distance from villages, so it is not proposed for recreation land uses. Regarding the "proximity to roads" criterion, the North Field and Komanos dumps are the closest to the road network and that is an additional fact that endorses the agricultural land use in these dumping sites.

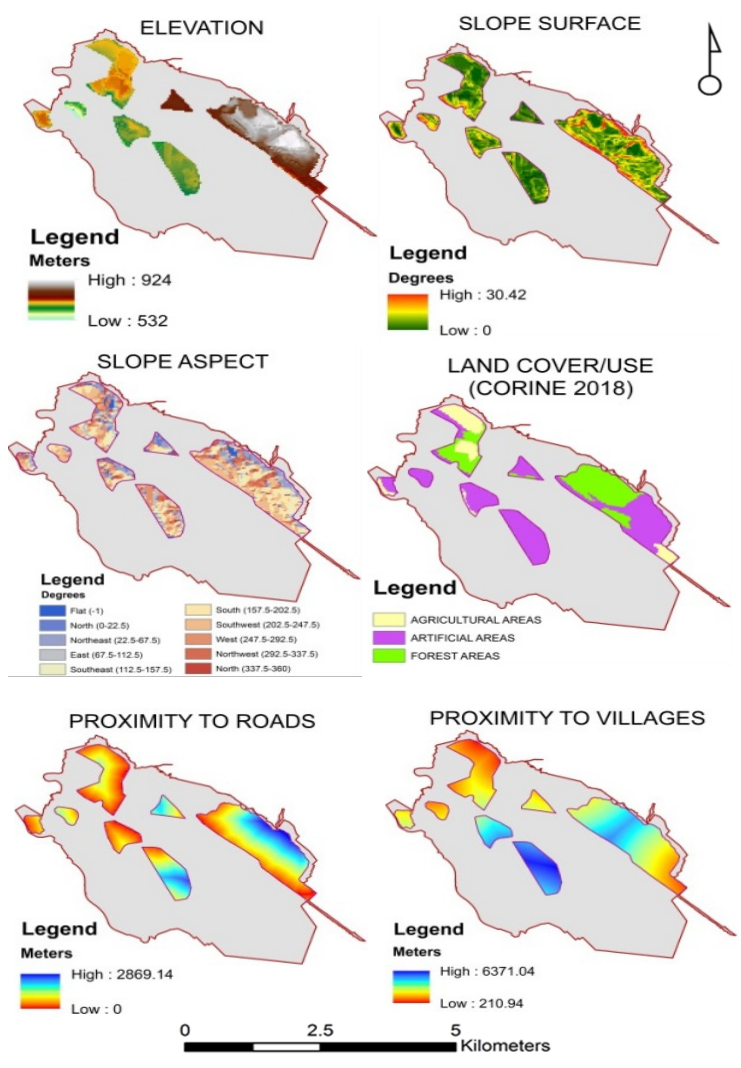

Fig. 8. The evaluation criteria of land-suitability analysis. 
In Figure 9 the spatial distribution of the agricultural land use suitability is presented, taking into consideration the classification of slope surface evaluation criterion. It is observed that the moderately suitable areas occupy most of the dumps' acreage, while the highly suitable areas overlap some already reclaimed areas. The areas that have slope surfaces higher than $8^{\circ}$ are not appropriate for agricultural use. The forest land use could be more suitable in these areas and this statement is validated by the fact that many of these surfaces have already been forestated. More specifically in the South Field dump where the steeper slopes are observed, forestation with Robinia Pseudoacacia, a tree that exhibits enormous high planting efficiency in the loose soils of dumps, has already been carried out.

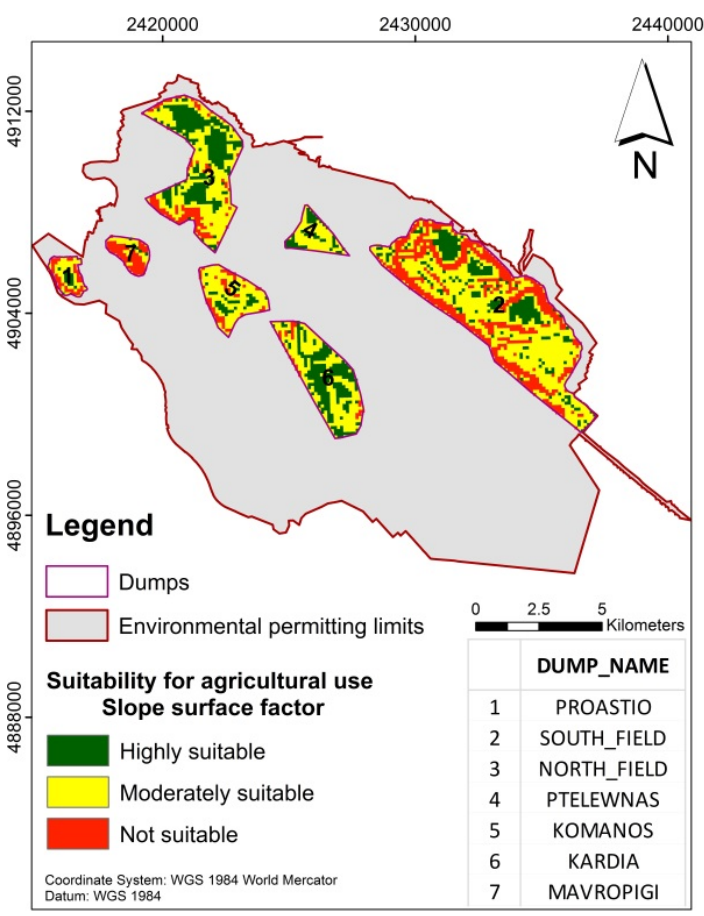

Fig. 9. Land suitability map for agricultural use according to slope factor.

The spatial distribution of land uses that is proposed in the frame of the present study is incorporated into the existing plan of land uses according to the Just Transition Development Plan of lignite areas (Figure 10). This plan concerns the land uses after the completion of the land reclamation projects and, in this context, it guides the entire environmental management strategy of the mine operator. It is obvious that the priority target of the EU for fast decarbonization of the energy sector, boost the development of photovoltaic parks due to environmental, economic, and social advantages: negligible carbon dioxide emissions, the creation of new jobs, new opportunities for investments, etc. This fact makes necessary the immediate implementation of land reclamation works focusing on areas that fulfill all the criteria for the construction of photovoltaic parks. 


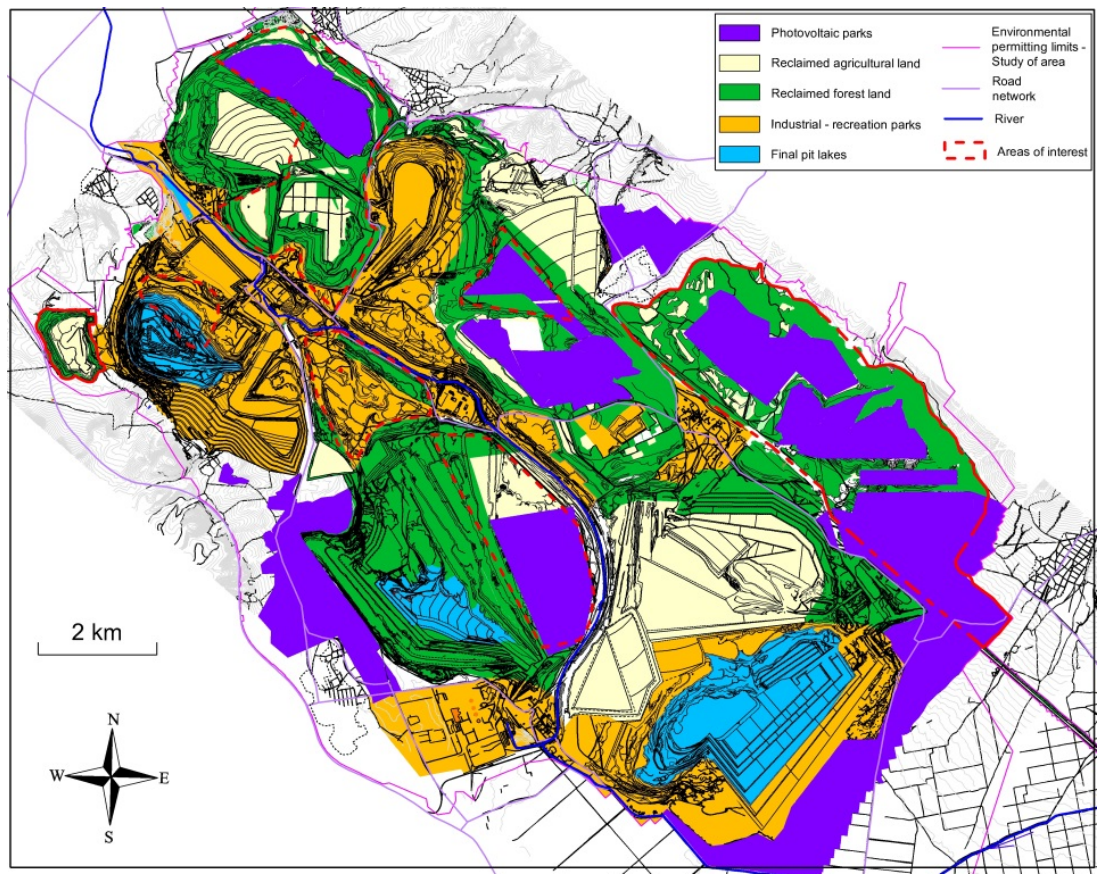

Fig. 10. The final estimated reclamation land uses.

\section{Conclusions}

In the present contribution, a preliminary evaluation of dumping areas was carried out, for several post-mining land uses and during the final reclamation to be proposed. According to the results of this analysis, the slope of the reclaimed land surfaces is the criterion that predominates the land use selection process. Flat slopes are suitable for agricultural use, gentle slopes favour the development of photovoltaic parks while steep slopes are more suitable for forest development. Important selection criteria are also the proximity to villages and roads.

Nevertheless, the criteria that have been investigated in this study are only some of the multiple criteria that affect the decision-making for land-use suitability. The incorporation of additional criteria, after a thorough investigation of site-specific parameters and a constructive dialogue of all the involved stakeholders, constitutes a complex procedure but of great interest to be investigated though. Moreover, a more detailed investigation is needed to determine the relative importance among the criteria and to identify the impact of several factors not related to spatial analysis, such as employment and legal requirements.

\section{References}

1 E.F. Lambin, B. Turner, H.J. Geist, B. Agbola, A. Angelsen, J.W. Bruce, et al. The causes of land-use and land-cover change: Moving beyond the myths. Glob Environ Change 11 (2001).

2 A.K. Braimoh Random and systematic land-cover transitions in northern Ghana. Agric Ecosyst Environ;113:254-63. https://doi.org/10.1016/j.agee.2005.10.019 (2006).

3 L. Nahuelhual, A. Carmona, M. Aguayo, C. Echeverria. Land use change and ecosystem services provision: a case study of recreation and ecotourism opportunities in southern Chile. Landsc Ecol;29:329-44. https://doi.org/10.1007/s10980-013-9958-x (2014). 
4

Q. Fan, S. Ding. Landscape pattern changes at a county scale: A case study in Fengqiu, Henan Province, China from 1990 to 2013. Catena;137:15260https://doi.org/10.1016/j.catena.2015.09.012 (2016).

5 K. Jahanifar, H. Amirnejad, M. Mojaverian, H. Azadi. Land change detection and effective factors on forest land use changes: application of land change modeler and multiple linear regression. J Appl Sci Environ Manag;22:1269. https://doi.org/10.4314/jasem.v22i8.20 (2018). H.T.A. El-Hamid, W. Caiyong, Z. Yongting. Geospatial analysis of land use driving force in coal mining area: case study in Ningdong, China. GeoJournal https://doi.org/10.1007/s10708019-10078-2 (2019).

$7 \quad$ M. Munthali, O. Botai, N. Davis, A. Abiodun Multi-temporal Analysis of Land Use and Land Cover Change Detection for Dedza District of Malawi using Geospatial Techniques. Int J Appl Eng Res; 14:1151-62 (2019).

H.J. Geist, E.F.Lambin. Proximate Causes and Underlying Deforestation. BioScience;52:143. 3568(2002)052[0143:PCAUDF]2.0.CO;2 (2002).

9 B. Zhang, Q. Zhang, C. Feng, Q Feng, S. Zhang. Understanding Land Use and Land Cover Dynamics from 1976 to 2014 in Yellow River Delta. Land;6:20. https://doi.org/10.3390/land6010020 (2017).

10 I. Masoumi, S. Naraghi, F. Rashidi-nejad, S. Masoumi. Application of fuzzy multi-attribute decision-making to select and to rank the post-mining land-use. Environ Earth Sci;72:221-31. https://doi.org/10.1007/s12665-013-2948-0 (2014).

11 F. Yang, G. Zeng, C. Du, L. Tang, J. Zhou, Z. Li. Spatial analyzing system for urban land-use management based on GIS and multi-criteria assessment modeling. Prog Nat Sci;18:1279-84. https://doi.org/10.1016/j.pnsc.2008.05.007 (2008).

12 J. Wang, F. Zhao, J. Yang, X. Li. Mining Site Reclamation Planning Based on Land Suitability Analysis and Ecosystem Services Evaluation: A Case Study in Liaoning Province, China. Sustainability;9:890. https://doi.org/10.3390/su9060890 (2017).

13 H. Soltanmohammadi, M. Osanloo, A. Aghajani Bazzazi An analytical approach with a reliable logic and a ranking policy for post-mining land-use determination. Land Use Policy;27:364-72. https://doi.org/10.1016/j.landusepol.2009.05.001 (2010).

14 J. Malczewski. Ordered weighted averaging with fuzzy quantifiers: GIS-based multicriteria evaluation for land-use suitability analysis. Int J Appl Earth Obs Geoinformation;8:270-7. https://doi.org/10.1016/j.jag.2006.01.003 (2006).

15 F. Pavloudakis, M. Galetakis, Ch. Roumpos. A spatial decision support system for the optimal environmental reclamation of open-pit coal mines in Greece. Int $\mathrm{J}$ Min Reclam Environ;23:291-303. https://doi.org/10.1080/17480930902731935 (2009).

16 MJ. Haigh Soil quality standards for reclaimed coal-mine disturbed lands: A discussion paper. Int J Surf Min Reclam Environ;9:187-202. https://doi.org/10.1080/09208119508964747 (1995).

17 J. Malczewski GIS-based land-use suitability analysis: a critical overview. Prog Plan;62:3-65. https://doi.org/10.1016/j.progress.2003.09.002 (2004).

18 A. Bozdağ, F. Yavuz, AS. Günay AHP and GIS based land suitability analysis for Cihanbeyli (Turkey) County. Environ Earth Sci;75:813. https://doi.org/10.1007/s12665-016-5558-9 (2016). 